\title{
Experiências criadoras na(s) infância(s)
}

\section{Creative experiences in childhood}

Maria Inês de C. Delorme é Professora Dra. do Departamento de Estudos da Infância (DEDI), da Universidade do Estado do Rio de Janeiro (UERJ).

Contato: delormemic@gmail.com

\section{Resumo}

Esse artigo apresenta e põe em discussão um trabalho que vem sendo desenvolvido por um grupo de alunos graduandos da Pedagogia da UERJ na disciplina Pesquisa e Prática Pedagógica (PPP, 2017-2019), referenciada no Departamento de Estudos da Infância. 0 objetivo é contribuir para a construção de um corpo teórico-prático multidisciplinar, voltado para professores, pedagogos e pais, que seja capaz de defender a importância de as crianças se desemparedarem, se reengajarem à cidade para brincar livremente com o fim de desenvolverem experiências criadoras com a natureza.

Esse trabalho pretende propor outras formas de estar com as crianças, de conhecê-las, de respeitá-las e de atendê-las como sujeitos únicos que excedam à racionalidade pura, por um escopo mais humanizado em que pesem a experiência e o sentido.

Palavras-chave: Crianças. Experiências. Brincadeiras.

Natureza. Cidades.

\section{Abstract}

This article presents and discusses a work under development by a group of undergraduate students from Pedagogy of UERJ, in the subjectResearch and Pedagogical Practice ( 2017-2019), in the Department of Childhood Studies. The goal is to build a multidisciplinary theoretical- practical body of studies, addressed to teachers, 
pedagogues, and parents, that is able to defend the importance of children being outdoors, that is, to reengage them to the city, to play freely in order to develop creative experiences with nature.

This work intends to propose other ways of being with children, knowing, respecting, andattending them as uniquesubjects, that go beyond pure rationality, by a more humanized scope in which experience and meaning are considered.

Keywords: Children. Experiences. Plays. Nature. Cities.

\section{Introdução}

Os recortes de narrativas de adultos e de crianças que a seguir apresentamos nos fazem tomar contato com modos muito diferentes, complexos, curiosos e até contraditórios, de sentir, de experimentar e de viver no mundo.

Fragmentos de conversas de adultos numa praça pública, da cidade do Rio de Janeiro:

\footnotetext{
1. "Não volto mais naquele parque! As crianças tropeçam na terra, nas pedrinhas e saem de lá todos ralados" (mãe, 28 anos).

2. "Não quero que minha filha descubra esses brinquedos altos porque, se ela gostar, eu vou ter um troço" (pai, 31 anos).

3. "Comprar para ele a sandália que ele quer, tudo bem, pode ser, mas desde que seja preta para todo mundo saber que ele é menino" (pai, 30 anos).
}

Há, também, fragmentos de conversas de crianças nesse mesmo espaço, onde dizem o que pensam, como entendem certas ordenações do mundo adulto. Elas expressam suas ideias e têm imagens sobre a vida, sobre o que os adultos pensam sobre elas e sobre o que elas querem para si:

\footnotetext{
1. "Minha mãe tem medo de morto. Ela não deixa ver o Chico matar galinha, lá no sítio, porque eu sou criança. Mas eu faço um buraco e enterro a cabeça e os pés delas. 0 Chico deixa escondido da minha mãe" (menino, 5 anos).

2. "Meu pai não deixa correr na rua nem no parque, para não cair. Mas eu corro na escola e não caio" (menina, 4 anos).

3. "Puxa, o que eu mais gosto é mexer na terra com água. Minha mãe e meu pai não deixam, dizem que ali tem bicho sujo que entra na barriga. Mas eu preciso fazer castelos com terra, água e folhas, desse jeito. Aí... eu não posso fazer nenhum castelo, nem de fada, nem de bruxa, e nem de nada" (menino, 5 anos).
} 
As crianças não devem se sujar de terra, mexer em plantas, lidar com a vida e a morte, ralar os joelhos, tomar banho de chuva, experimentar alturas, sentir certas vertigens! Não se trata de uma visão nostálgica da vida, mas apenas de listar algumas pequenas experiências que "os adultos tiram" da vida das crianças em nome de cuidado, proteção e segurança.

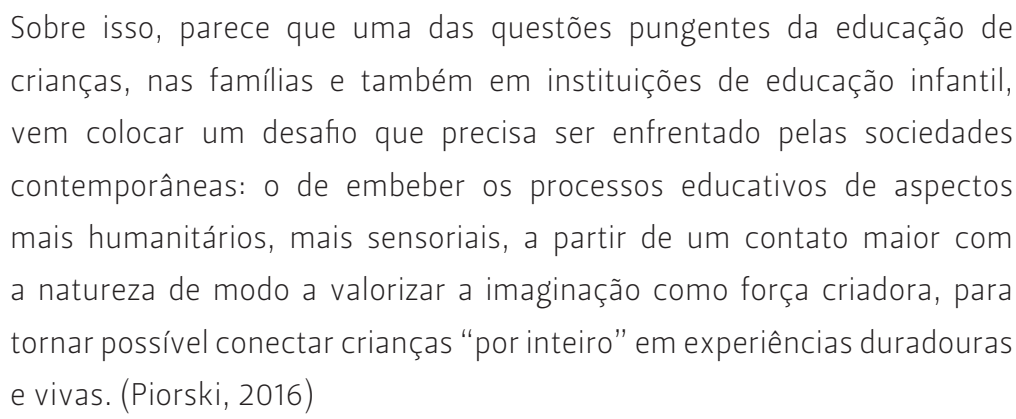

Pode-se dizer que os trabalhos institucionais desenvolvidos por adultos/professores com crianças vêm demonstrar que são propostas certas "experiências" a elas, aquelas que os adultos julgam valiosas. Sim, nós professores sabemos instituir bem essa dinâmica de proposição de atividades como se fossem experiências, umas atrás das outras, valorizando a sua clareza de comando e a consequente atuação das crianças, sem o apuro e a sensibilidade necessários às experiências que chamamos de criadoras. Podemos estabelecer novas dinâmicas e convidar as crianças às experiências quando lhes garantirmos liberdade de percurso, tomada de decisões, espaço e tempo para vivências subjetivas, imaginativas, que nem sempre podem ser traduzidas em palavras.

A natureza da imaginação humana é cambiante, ilimitada e cobra de nós, paralelamente, o reconhecimento da razão com seus métodos e sua organicidade se pensamos em desenvolvimento e aprendizagem infantis, mesmo que organizados em grupos de conhecimentos, competências e habilidades, desde que não se perca de vista a vida imaginária.

Pode-se dizer que os processos educativos amplos, em suas diferentes instituições, -já há algumas décadas vêm se fortalecendo "academicamente" a partir de questões que nos enfraquecem como sujeitos, como seres humanos, como sujeitos de/da cultura. Talvez a infância venha a ser o único reduto que contempla as crianças inteiras, com todas as suas dimensões integradas, vivas e com sentido, apesar dos esforços reiterados de didatizar, pedagogizar e de restringir, assepticamente, a educação ao ensino de conteúdos e de disciplinas estanques. As crianças 
resistem. As crianças sobram para além do que planejamos para elas. Nunca os adultos as dominam nem as controlam inteiramente. E seus escapes aparecem nas fendas que criam para conseguirem ser como são, a despeito das atividades, dos tempos e dos espaços que os adultos "estabelecem" para elas.

Sabe-se que todas as crianças passam por algumas fases semelhantes, do nascimento à vida adulta, mas é importante valorizar as vivências de cada uma delas como aspectos diferenciadores entre todas, como elementos que garantem vidas e personalidades únicas, unas e diferenciadas.

Assim, embora se deseje fazer algumas defesas como sendo respeitosas, fortalecedoras e importantes para a vida de todas elas, nada justifica não valorizar suas subjetividades, suas formas únicas de ser, de sentir e de estar no mundo. Ao contrário, talvez seja a brincadeira livre em contato com a natureza uma circunstância necessária e favorecedora para se encontrarem consigo mesmas, com suas imagens pessoais, sem pressa, no tempo de cada uma.

Pode-se dizer que os escapes que as crianças descobrem e usam no dia a dia, e que passam pelas fendas do controle dos adultos, vêm confirmar que a base, ou o esteio das relações das crianças com o mundo, está no seu mundo imaginário, na sua capacidade de se encontrar e se distanciar, se apropriar e distorcer, recriar e remontar o mundo segundo sua lógica própria, que difere completamente da do mundo adulto.

Passou da hora de buscar e de conhecer o que são, na verdade, as experiências vivas que fazem sentido para a vida de cada criança, de grupos de crianças. E, com isso, pensar na validade de currículos formatados pelos adultos para elas e também na qualidade de relações estabelecidas pelos adultos de referências, com elas.

\section{Histórias, conversas e experiências de crianças e de adultos}

A cada ano letivo, os professores da universidade que vão oferecer a disciplina "Pesquisa e Prática Pedagógica (PPP)", por quatro períodos consecutivos, têm uma data para apresentar aos novos alunos a sua temática. Em seguida, os alunos escolhem 0 PPP em que desejam se matricular e, assim, foi organizada essa turma de alunos. A turma se configura com 25 alunos, no máximo, e tem suas especificidades para a formação de professores. Como o seu próprio nome indica, é desejado que sejam efetivas 
e permanentes as relações entre teoria e prática. 0 fato de a disciplina ser oferecida em quatro períodos subsequentes, mantendo-se o docente e o grupo de alunos, favorece o vínculo afetivo e, com isso, a pesquisa, a reflexão e a busca coletiva de mecanismos de superação dos entraves clássicos dos contextos escolares.

Isso pede, também, uma compreensão mais adensada da realidade educacional da cidade, do estado e do país e que envolva, ainda, o grupo com temáticas interdisciplinares que provoquem o entendimento da indissociabilidade das disciplinas pedagógicas. A prática desejada de pesquisa por meio de leituras de textos e de livros, o contato e a confecção de resenhas, de artigos, de fichamentos, debates, discussões ampliadas com convidados, filmes e vídeos, a participação em congressos e em seminários etc., permitem vivenciar essa conexão viva e direta das práticas com as teorias. Com isso, essa disciplina deve contribuir, também, para que grupo de alunos venham a se fortalecer na produção de escritas mais acadêmicas, para que, mais à frente, cada um escolha e elabore projetos individuais de pesquisa, no tema e na área em que sintam ressonância ideológica, afetiva e acadêmica, para a conclusão do curso.

No primeiro período, selecionamos autores, teorias e suportes para o que queríamos estudar juntos. Em seguida, planejamos visitar determinados espaços públicos altamente frequentados por crianças e famílias, para oferecer algumas alternativas de brincadeiras livres para as crianças, o ato de brincar por brincar. Ao mesmo tempo, o grupo deve observar, conversar, registrar esses momentos num bloco de notas e também com fotos e filmagens. As famílias também são chamadas para conversar, sem que haja qualquer peso de entrevista ou de questionário.

Assim, pelo menos por duas vezes ao ano, esse grupo de 25 alunos da Graduação em Pedagogia ocupa determinados espaços públicos da cidade, numa manhã de sábado, para acompanhar crianças em uma ação que é parte de um projeto que se chama "Papo de Pracinha1", e que tem todas as suas ações explicitadas e expostas, com registros fílmicos e fotográficos no site de mesmo nome. Esse projeto nasceu fora do âmbito universitário, como uma iniciativa de duas professoras universitárias, Angela Borba (UFF) e a autora deste texto (UERJ), no ano de 2015. Em 2017, parte desse projeto foi envolvida e aprofundada com esse grupo de alunos na disciplina PPP: Crianças e Natureza nas Cidades, que veio a se tornar um Grupo de Extensão também.
1. O Papo de Pracinha é um espaço de diálogo sobre a vida das crianças e de suas famílias nas cidades. Esse espaço envolve diferentes projetos, tais como um site com publicações semanais, ações com as crianças na cidade, produção de livros etc. Investimos numa educação não consumista e sustentável, apoiada na imaginação e na capacidade de as crianças criarem brinquedos e brincadeiras a partir do reuso de madeiras, tecidos e outros materiais (www.papodepracinha. com.br). 
As ações desse projeto são discutidas em seus fundamentos e práticas em quatro tempos semanais de atividades, em sala de aula e na universidade. Além das discussões, são feitos passeios e visitas pela cidade para identificar praças e espaços públicos já eleitos pelas crianças como "espaços de brincar". Nesse percurso, já foram promovidos encontros do "Papo de Pracinha" à beira da Lagoa Rodrigo de Freitas, no Parque Guinle, na praia etc., sempre sob o convite: "Bora Lá, brincar na praia", por exemplo.

Como essa ocupação nos espaços públicos é itinerante e, sendo assim, não acontece sempre em um mesmo espaço da cidade, o público infantil é conhecido pelo grupo no momento do evento. Costumamos trabalhar com entrevistas narrativas, com crianças e seus responsáveis, também com fotografias que acontecem durante a observação das crianças em interação, fora ou dentro das brincadeiras propostas, que geram registros escritos em pequenos cadernos de campo. Os alunos se organizam em pares de pesquisadores que conversam com os pais ou responsáveis no formato de entrevistas narrativas semi-roteirizadas, enquanto as crianças brincam. Em todos os casos, esse trabalho só pode se desenvolver dessa forma quando autorizado pelos pais ou responsáveis, no que diz respeito ao direito de uso de imagem e de voz. E, ainda assim, mesmo que já autorizadas pelos adultos, submetemos nossas fotos e filmagens à vontade e ao desejo de cada criança para falar, para se deixar fotografar etc.

0 ambiente geral de cada encontro acontece sempre ao ar livre, em contato com a natureza, onde são alocados pequenos espaços de brincadeiras, mais ou menos organizados, que podem ser vivenciados livremente porque permitem às crianças entrar e sair de cada um deles, na hora e da maneira que quiserem, "no tempo delas". Em cada um desses pequenos espaços, ou microgrupos, há pelo menos dois alunos. Eles não têm a função de tomar conta, controlar, organizar a brincadeira e nem, tampouco, o compromisso de "entrevistar" as crianças. Ao contrário, eles estão ali para observar e para serem observados como "adultos outros", disponíveis também para serem conhecidos pelas crianças, para conhecê-las, para registrarem o possível, acompanharem, interagirem, conversarem, quando for o caso, e ajudarem, se forem solicitados.

Os materiais disponíveis em cada uma das estações de brincadeiras são diferentes, embora atendam a alguns requisitos comuns, como o fato de em sua maioria serem encontrados na natureza: folhas, gravetos, grãos, sementes, terra, água de chuva, blocos de madeira 
de reuso, tintas feitas com pigmentos naturais. Também levamos tecidos, bolas de sabão, fantasias e máscaras coloridas. Buscamos alimentar a criação, a liberdade e a imaginação infantis.

Esse trabalho só pode ser desenvolvido com um grupo que se afine em pontos centrais, como vem acontecendo com essa turma de alunos de Pedagogia. Nessa interação do grupo-pesquisador com a globalidade das experiências vividas e imaginadas pelas crianças acabam emergindo recorrências, discrepâncias e ambiguidades que, de volta à universidade, semanalmente, nos fazem questionar certas escolhas e as decisões prévias que tensionam a nossa capacidade de flexibilizar.

O caderno de campo e a câmera fotográfica do celular são fontes de coleta de dados e da geração do material de análise e, apesar dos cuidados, sempre refletem a "personalidade" do grupo.

Foram estabelecidas a priori alguns pressupostos sustentadores para esse estudo, que procuramos respeitar todo o tempo. 0 primeiro se refere a uma concepção de criança como sujeito de direitos, ativo e participativo, que se caracteriza pelo que é, desde que nasce, e não pelo que lhe falta sob a ótica do senso comum e do mundo adulto. Uma segunda questão exige garantir a observação, a escuta e a fala no contexto delas, em espaços conhecidos por elas, como sujeitos únicos, ainda que como partes de uma totalidade social. Nisso, estaria incluída a preocupação em conhecer os fenômenos daquela determinada realidade social. Uma terceira questão consiste em garantir que os registros escritos estejam centrados numa compreensão pautada na descrição, sem julgamentos de valor, em que se possa ver a relação entre as crianças, delas com os adultos e, também, com aquele(s) espaço(s) simultâneos de brincar na natureza. 0 quarto pressuposto se refere à intenção de tornar os nossos encontros na universidade um espaço de compreensão e de reflexão, onde a profundidade do conhecimento deve valer mais do que sua precisão e do qual não precisaríamos esperar nenhum "efeito conclusivo", no sentido de alcançar verdades fechadas ou definitivas. Como vem acontecendo, só durante o período de permanência, em cada encontro, num determinado espaço da cidade, junto com as crianças é que os aportes teóricos são postos à prova.

\section{As sustentações teóricas}

Eu não quero uma cidade infantil, uma cidade pequena. Não quero uma cidade montessoriana. Quero uma cidade para todos. 
E para estar seguro de que não esquecerei ninguém, escolho o mais novo. (TONUCCI, 2016, s/p²)

Não é tarefa simples defender o espaço das crianças nas cidades, nos dias de hoje, diante dos cenários, brasileiro e carioca, de violência e de insegurança. Os adultos se protegem como podem, saindo de casa menos que o desejado e, com isso, também as crianças ficam com experiências restritas ao espaço de suas casas e, na melhor das hipóteses, ao da instituição de educação infantil que frequentam.

Brincar na rua, nas praças e nos espaços "mais austeros e enrijecidos" das cidades não são atividades habituais para as crianças que vivem sob os cuidados e a educação de seus pais ou responsáveis. Brincar nesses espaços sugere, quase sempre, muito risco para elas, além de se estabelecer uma relação imediata dessas crianças com abandono, miséria e negligência dos adultos.

A cidade maravilhosa, com beleza exuberante e natureza invejável, se torna invisível e inviável sob a ótica do medo e da (in)segurança. Embora isso tudo seja verdade, há algumas prerrogativas interessantes no sentido de mudar a vida nas grandes cidades e que poderiam ser implementadas também no Rio de Janeiro: lindo, desigual e complexo.

Esperar que o poder público volte seu olhar e foco para as crianças, no Brasil, vem se configurando como algo quase impossível, apesar da luta permanente e cada vez maior por parte da sociedade para alterar esse quadro de desesperança.

É possível identificar movimentos nesse sentido capitaneados por ONGs, como o Instituto Alana, por associações de pais e até por algumas universidades que põem em pauta e que fazem acontecer saídas possíveis que alimentam ações continuadas, organizadas e multidimensionadas no sentido de "desemparedar" as crianças.

Assim, ir aos espaços onde as crianças ainda costumam frequentar, acompanhadas de adultos, nos fins de semana e feriados, pareceu ser uma boa alternativa para conhecer o que elas pensam, como interagem, suas brincadeiras, como sentem, vivem e o que temem em seus "espaços de brincar", e diz muito para nós, professores.

Quando observamos as crianças nesses espaços, confirmamos a existência e manutenção de um olhar comum, construído historicamente, que informa ser a cidade onde vivem algo que Ihes foi dado, pronto e acabado, onde lhes cabe cerimoniosamente contemplar, gostar ou não dela.
2. Disponível na internet: http:// cidadeseducadoras.org.br/reportagens/francesco-tonucci-a-crianca-como-paradigma-de-uma-cidade-para-todos/, 2016. 
As crianças têm direitos sobre a cidade, sobre os espaços públicos embora raramente sejam chamadas a dizer, a expressar o que pensam e desejam em relação a eles. Estar disponível para as crianças implica uma escuta valorosa de um e de outro, o reconhecimento do valor de suas existências, das histórias de cada um, do valor de serem quem são.

Tonucci é um pensador, pedagogo e desenhista italiano nascido em 1940 que se tornou um defensor ferrenho da participação social da infância na discussão pública sobre as cidades. Ele criou o projeto Cidade das Crianças, que aposta em sua transformação a partir do olhar das crianças, e lamenta que poucos prefeitos/ políticos sejam capazes de escutar as crianças de verdade. Segundo ele, as políticas públicas urbanas têm como tarefa garantir o direito ao brincar de meninos e meninas, porque a brincadeira é a "experiência mais importante na vida de homens e mulheres, funcionando, ao longo da vida como um cimento sobre o qual se constroem nossa formação e nossa cultura" (TONUCCI, $2016, \mathrm{~s} / \mathrm{p})$, e isso precisaria ser conquistado nos primeiros anos de vida, brincando.

Tonucci se diz impactado com o fato de as crianças hoje viverem emparedadas em suas casas, ao mesmo tempo em que estão conectadas com o mundo inteiro, com enorme mobilidade cognitiva. E segue confirmando o paradoxo identificado e citado na introdução desse artigio:

\footnotetext{
As crianças pedem, à escola e à cidade, mais autonomia e mais liberdade. E seus pais pedem, à escola e à cidade, mais controle, mais vigilância e mais proteção. São duas visões conflitivas e devemos escolher de que lado estamos $^{3}$. (Tonucci, 2016, s/p)
}

Torna-se igualmente complexo e rico defender a apropriação dos espaços da cidade pelas crianças com uma tônica voltada para as experiências com a natureza, e isso não implica dizer que os aspectos culturais fiquem esquecidos ou desvalorizados mas, ao contrário, se imbricam numa relação dinâmica que precisa ser considerada. Como exemplo disso, buscamos entender também como cada um de nós identifica os espaços de natureza na cidade, as possibilidades de acesso e de interação cuidadosa com eles, sem romantismo, o que pode, e também o que não pode, ser visto por crianças e adultos como questões importantes.

A "natureza, nas escolas", ainda hoje, muitas vezes se restringe a guardar bichinhos em gaiolas, àquelas plantinhas que são regadas, adubadas, estudadas mas que nem sempre são
3. Disponível na internet: http:// cidadeseducadoras.org.br/reportagens/francesco-tonucci-a-crianca-como-paradigma-de-uma-cidade-para-todos/, 2016. 
relacionadas ao ambiente natural maior de que são parte. Também não é desejado radicalizar e estabelecer que o contato direto com a natureza seja simples se pensamos em morros e montanhas, rios, mares, ventos e luz do sol, o que é praticamente impossível em grandes cidades.

Há algo de sagrado, de misterioso e até de assustador nesse contato direto com a natureza. No afã de dominar as forças do mundo natural, o ser humano precisou entender os seus limites e foi compelido, digamos assim, a tomar a natureza como indomável, como insubordinável em certos aspectos e até mesmo impermeável a parte de certos avanços das ciências.

Esse emparedamento que gera o distanciamento contemporâneo verificado entre crianças e adultos em relação à natureza se justifica, até certo ponto, por essa compreensão romântica e reificada que viria impor respeito e a mantê-la intocada. Por outro lado, essa mesma postura talvez explique uma atitude predatória das pessoas em relação à natureza. A cidade, que é de todos, acaba não sendo apropriada afetiva e efetivamente por ninguém. "Quem é o dono da cidade?", "Quem cuida da cidade?" e "Onde está a natureza na cidade?" são perguntas para as quais buscamos respostas de crianças e adultos, nesse trabalho. 0 que dizem as crianças:

Eu e meus amigos temos uma casinha para fazer coco e xixi, lá na florestinha
atrás da escola. Mas isso é segredo, é muito segredo - menino, 5 anos.

Minha mãe não deixa a gente brincar de morto e vivo. Ela nunca sabe que a gente morre e "sobreveve" de novo - menina, 6 anos.

Quando meu cachorro nasceu, meu avô disse que ele era feio que nem uma gambá. Eu acho ele lindo, e ele é cachorro, não é gambá. Eu acho que ele come ratazana, mas eu nunca vi. Ele (o cachorro) sabe que eu tenho medo de ratazana que mora no telhado, escondida, e ele me protege. Meu avô me irrita muito - menino, 6 anos.

Desse modo, entendemos que a natureza deveria ser um cenário de vida para visitas, inspeções e brincadeiras que proporcionem um tipo de experiência qualificada e duradoura, coloridas por imagens internas que geram histórias e narrativas expressivas e alentadas na primeira pessoa.

Que natureza e em que dimensões ela pode ser acessível às crianças de tal modo que lhes permita buscar as minúcias das coisas, que possa atender as evocações de experiências mais 
profundas e sensíveis? Talvez seja possível afirmar que a criança não produza arte, mas que ela seja a própria arte, já que sua linguagem é sempre a da imaginação, enquanto sua razão analítica está, aos poucos, se constituindo sem que suas intuições e suas sensibilidades precisem morrer. Piorski (2016, p.57) diz que a criança habita o poder mágico das imagens enquanto "o poeta ou o filósofo recorrem à produção estética buscando recuperar esse poder que a criança já tem".

Os adultos em geral não acreditam, não têm interesse e demonstram até certo medo de investir nesse apuramento sensível de "olhar vagabundo", despretensioso, de suas crianças sobre o mundo. A imaginação e a criatividade dependem de certa desocupação, "de vazios", para se nutrirem.

Gandhy Piorski é um educador, artista plástico, teólogo, mestre em Ciências da Religião e também um pesquisador maranhense nas áreas de cultura e de produção simbólica, antropologia do imaginário e filosofias da imaginação. Ele estuda o brincar e o brinquedo há mais de 20 anos e viaja incessantemente para buscar conhecer as crianças do Brasil. Nessas viagens, ele identificou uma intimidade operacional por parte das crianças, guiada pela imaginação criadora, muito intensa e profunda, em relação aos elementos da natureza. Isso fez com que ele iniciasse um estudo sobre o brincar em sua relação com a terra, o fogo, o ar e a água. Em seu primeiro livro, Brinquedos do chão: a natureza, o imaginário e o brincar (2016), o autor busca compreender o universo do brincar com a terra em diálogo com o reino imaginário da criança.

Segundo o autor, as experiências constituidoras das subjetividades humanas, aquelas que integram aspectos internos e externos da existência humana, não podem prescindir de se apoiar nas "filosofias da imaginação", que valorizam certos aspectos vitais e sensíveis que foram desvalorizados pelo Ocidente. Assim, diante da prevalência de uma lógica que buscava traduzir a realidade das coisas, fomos nos prendendo à luz e à claridade da vida, do que nos remete "à luz do dia", podendo dizer que a ideia que remete ao que é noturno, a vida onírica, tenha sido deixada de lado. Assim, também os mitos foram explicados fora do sujeito, sempre modelados pelo real, o que não parece suficiente. Ainda segundo ele, as formas e as manifestações da água, do fogo, das flores, plantas etc. têm uma relação direta com a estrutura básica da vida, da natureza humana, que não pode ser esquecida.

As populações indígenas, os seres das florestas, os quilombolas ainda hoje têm uma relação sensorial refinada que nutre suas formas 
próprias de ser e de estar no mundo. Nós, cosmopolitas, perdemos em grande parte essa conexão com o mundo natural e sensível, mas, ainda hoje, se há necessidade de relaxar, de se reestruturar internamente e até de buscar alternativas objetivas para os problemas reais, é comum ir ao encontro da natureza como refúgio para um reabastecimento, para uma religação com si mesmo, para uma renovação de energias físicas, mentais, espirituais.

Essa religação, de origem "re-ligare", de onde se origina a palavra religião, é estabelecida pela capacidade de imaginar, de pensar por imagens, o que é próprio das crianças e das infâncias. $\mathrm{E}$, para o desenvolvimento de uma imaginação criadora, aquela que não se opõe ao ato criativo, ao contrário, o potencializa, segundo Baudelaire, poeta parisiense e teórico das artes, morto em 1867, a imaginação deveria ser tomada como a "rainha das faculdades". Ainda para Baudelaire (1993), a imaginação seria diferente da fantasia, que poderia levar "a devaneios e ideações vagas". 0 autor fala de imaginação criadora como capaz de iluminar seu intelecto para revelar ao artista o que ele tem como ideal, que nada tem a ver com padrão de perfeição, mas está diretamente relacionada à sua imagem íntima e profunda. Desse modo, Baudelaire tomava essa psicologia do ato criativo, enaltecedora da imaginação, como reconstrutora da relação entre a arte, a natureza e a verdade.

Esse pensamento mágico que se configura na infância na vida da criança não obedece a uma métrica quantificadora nem avaliadora, e desconhece todos os ideais de perfeição. Como acontece também com as expressões artísticas, esses ideais não se subordinam, se insurgem contra a ordem, contra as cápsulas e as caixas. Também não podem obedecer aos padrões de abundância segundo certos critérios de produtividade que podem ser notados, por exemplo, pelo volume das pastas de "trabalhinhos escolares" que vão para a casa e que são ainda muito valorizados pelos adultos, não só pelos pais, mas também por algumas instituições de educação infantil. Imaginação e expressões artísticas não viajam em pastas, mas têm suas próprias asas.

Bachelard, filósofo e poeta francês que viveu de 1884 a 1962, , deu destaque à vida do homem na sua relação com a matéria da vida, vasculhando o lugar das sensações humanas, os fractais da emoção humana. 0 poeta reconheceu ter sido a vida imaginária, por assim dizer, desconsiderada e desconhecida da ciência e, para ele, a imaginação como uma força que poderia ocupar o lugar do quarto reino, para além do vegetal, mineral e animal. Um quarto reino que chamaremos aqui de "imaginal" e que envolveria todos os outros. 
Segundo o filósofo, o fogo e a chama, dentre os objetos que nos fazem sonhar, é um dos melhores operadores de imagens. Está na multiplicidade e nos detalhes das imagens a possibilidade de nos fazer sentir a força das chamas imaginadas que "inflamam o psiquismo" e conclui afirmando que "todo sonhador inflamado é um poeta em potencial. Todo sonhador inflamado está em estado de primeira fantasia" (BACHELARD, 1993, p. 10-11).

A vida que existe em nós, para além da linguagem, está na base da formação humana e nos remete a uma relação "atritosa", curiosa e interativa nossa com a natureza, com o fogo, com a terra, com os dias e as noites, com o sol e a lua, com a vida e a morte, com as transformações e os mistérios etc. E, ao longo da história, os seres humanos foram produzindo narrativas impregnadas dessas matérias de vida. Essa memória substancial do mundo, portanto, precisaria ser acordada por uma vida mais conectada com o mundo natural, com a natureza. Essa relação permitiria às crianças expandirem suas camadas de proposições subjetivas na busca de compreender as coisas, já que as matérias primeiras do mundo seriam capazes de despertar essa memória substancial das interioridades infantis, humanas.

$E$, caso não entendêssemos a imaginação como força, não teríamos como explicar os pesadelos, as tormentas, os medos, essas forças e símbolos que guardamos em nós a que as crianças e os artistas têm acesso facilitado.

Propor uma reflexão, no campo da Educação, para buscar identificar os caminhos da alma, por onde a alma transita, qual a sua relação com o corpo, que aceite sua existência sem vinculação com as diferentes cosmovisões e religiosidades, é um desafio imenso. Uma ousadia, pode-se dizer, e, ao mesmo tempo, um exercício acadêmico que, se aceitamos, exige repensar toda a relação de adultos com crianças, os "currículos" propostos, a organização dos espaços a elas destinados e também as cidades.

Como defendeu Bachelard, a chama, mas não só ela, nos força a olhar. Ela evoca milhares de lembranças que podem ser resgatadas através de uma memória muito antiga, além de sonharmos de forma muito semelhante às outras pessoas, além de sermos capazes de lembrar e de trazer para o presente essas lembranças, como todo mundo. Então, diz o filósofo, "seguindo uma das leis mais constantes da fantasia diante da chama, o sonhador vive em um passado que não é unicamente seu, no passado dos primeiros fogos do mundo" (2003, p.11) 
Pensando nessa capacidade evocativa defendida pelos filósofos e poetas, que têm na imaginação sua força, escolhemos propor às crianças pequenos espaços simultâneos de brincar, que pudessem convidá-las a libertar suas memórias antigas, que por sua vez, talvez possam ser chamadas de arquétipos, como pensou o suíço Carl Gustav Jung (1875-1961), discípulo de Freud. Jung foi psiquiatra, psicoterapeuta e fundou a psicologia analítica. Ele propôs e desenvolveu conceitos como os de personalidade extrovertida e introvertida, de arquétipo e de inconsciente coletivo. Seu trabalho até hoje é influente na psiquiatria, psicologia, ciência da religião, literatura e áreas afins. Este autor entendeu a natureza humana como de base simbólica e, por isso, foi um estudioso dos símbolos, da filosofia ocidental e oriental, da alquimia, da astrologia e da sociologia, bem como da literatura e das artes. Talvez, por essas aproximações, tenha sido considerado por muitos um místico. Segundo ele, entendemos como arquétipos os conjuntos de "imagens primordiais" que se originaram de repetições progressivas de uma mesma experiência, durante muitas gerações, que ficam armazenadas no que chamamos de inconsciente coletivo.

Sob esse viés, o nosso grupo convida as crianças a "brincarem de comidinha", por exemplo, com grãos, carvão, favas, pedras variadas, folhas verdes e secas, panelinhas, talheres e pequenas travessas de madeira, com tonéis de água de chuva. Mais do que agradar às crianças, apenas, interessou-nos garantir o livre brincar e o contato com a natureza como ferramentas essenciais para o que chama Piorski de uma "pedagogia de repercussões internas", a partir de um mergulho nos sentidos. Essa ação da criança sobre a natureza permite a criação do que ele chama de brinquedo livre, aquele que é construído pela criança e que, por isso, traz em si a própria alma da criança. E nesse percurso, diz o autor, "toda a gestualidade, todo dizer e toda pausa para um devaneio é também matéria natural e orgânica para os brinquedos do chão". (2016, p.49)

O chão é tratado por este autor como um elemento que rege a Terra (virão ainda os Brinquedos do Fogo, do Ar e da Água). Piorski defende que a imaginação telúrica é a que abre as portas da fantasia, das brincadeiras e das práticas culturais infantis. Telúrica porque envolve o que está relacionado ao planeta Terra e, também, à influência de cada tipo de solo, de cada chão da região em que as crianças vivem.

As crianças se surpreendem quando perguntamos a elas como é o chão da casa delas, como é o chão de suas escolas, das ruas 
por onde passam, como é o chão onde pisam. Quantos de nós proporcionamos às crianças que pisem descalças em chãos mais e menos habituais e notamos o que elas criam e imaginam na relação com cada textura que pode ser pedra, areia, terra, barro, um fundo de rio, madeira, asfalto etc.. E cada textura tem e conta, também, uma história única. Não se pode acreditar que esse contato de crianças com diferentes tipos de chão não seja transformador $r$ desafiador para seus pezinhos.

Piorski diz que os brinquedos de chão fincam as crianças no mundo e que também as acordam para firmar o mundo em si. Seria, portanto, essa relação primeira das crianças com o chão e a terra decorrente de acordos nem sempre pacíficos com a realidade, o que "dá corpo" à criação de imagens sobre sua origem e a origem do mundo, do que é oculto e mágico, da solidão e da morte como eternidade (2016, p.53). Os brinquedos do chão e da terra, nesse diálogo da criança coma natureza, incluem todas as representações e mimeses da vida social. Vale dizer que não são cópias dessa vida social, mas releituras muito subjetivas, feitas pelas crianças nessa relação com a natureza, com si mesmas e com outras crianças. Aí cabem as cabaninhas, a casinha, a fazenda, os animais construídos, as comidinhas com grãos, pedrinhas e folhas, os carros de boi, de madeira, de vara, de lata, de osso, os materiais de modelar e, também, as representações simbólicas de casamentos, de nascimento, de trabalho, de beleza, de rituais religiosos e tantas outras coisas que vivem e/ou imaginam.

Oferecemos, também, brinquedos e brincadeiras que remetem ao ar e aos movimentos como bolhas de sabão, pipas, certos tecidos pendurados que voam ao vento, pernas de pau, cordas, bambolês, bolas, deslocamentos com equilíbrio em caminhos suspensos em raízes de árvores, atividades com ar, como brincar com bolhas de sabão, cabanas e túneis. Também há fantasias que envolvem asas de aves (arara, garça, urubu e outros), rabos variados (zebra, leão, jacaré, dinossauro etc.), máscaras, adereços em geral, e espelhos. Desenhos e montagens podem ser feitos com gravetos, folhas, pedras, pedaços de madeira, tocos com espessuras e texturas variadas. A brincadeira e o brinquedo provenientes dessa experiência de brincar na e com a natureza "são a porta de acesso às reservas simbólicas da produção humana", diz Piorski (2016, p.51)

Nesses encontros, as brincadeiras são livres, gratuitas e todo o material utilizado pertence ao acervo do Papo de Pracinha. Dele só fazem parte material de reuso, sustentável e não mecanizado/automatizado. 
Voltando aos estudos acadêmicos, pode-se observar que as diferentes teorias têm convergido no sentido de explicar e entender como as crianças aprendem, se desenvolvem, pensam e sentem. Como elas se constituem como sujeitos únicos, como pessoas, em interação social, na cultura ainda são perguntas que encontram respostas diferentes, em áreas diferentes, mesmo que afins, e muitas vezes ainda reafirmam o equívoco de que elas se desenvolvem em etapas sequenciadas e iguais, a despeito da cultura. Não é fácil quebrar a valorização exacerbada dos "preceitos biológicos" quando esses têm o peso de ciência e, ao mesmo tempo, esses saberes científicos não têm força para prever, controlar, nem domesticar as crianças em suas diferentes infâncias, espaços-tempos e culturas.

0 mundo ocidental, envolto na corrente racionalista do século XIX, trouxe para a Educação e para as Ciências Humanas um caráter científico que orientou um movimento de educação asséptico, desarticulado, que não afeta nem é afetado pelas crianças, sem sentido e desvinculado das intuições e dos sentidos, do senso ético e estético, distanciando os saberes das experiências sensíveis, esquadrinhando a vida das crianças pelas medidas rígidas dos ditames considerados científicos.

0 pensamento lógico encaixa, atribui propriedades, relaciona grandezas e formas e é seguro o bastante para explicar o mundo. Cria um pavimento comum, seguro e confortável, mas onde nós, humanos, com a nossa grandeza, não cabemos.

A partir da metade do século XX o Brasil foi marcado por uma forte influência racionalista que gerou uma valorização do chamado pensamento lógico que, ainda hoje, trabalha de modo a desconectar o saber dos desejos, a lógica da fantasia, desvalorizando o mundo imaginário da criança. Elas, as crianças, pensam por imagens que têm cheiros, sons, registros de texturas, continuidades e descontinuidades, e que são bem diferentes das formas mais características do mundo adulto.

Parece estar explicado, portanto, por que a brincadeira livre, as experiências sensíveis e o contato com a natureza perderam espaço para ensinamentos encaixotados e identificados como sendo relativos a cada uma das áreas diferentes dos conhecimentos. 0 fato de a brincadeira livre não exigir um espaço próprio para que ela aconteça, o tempo de duração da brincadeira também não poder ser estipulado pelos adultos e a sua falta de resultados aparentes ajudou a desqualificar uma atividade essencial para a vida das crianças, como afirma Brougère (1994, p. 7-24). 
E nesse sentido, o mundo imaginário, ou simbólico, que precisa ser alimentado, é a possibilidade de expressão mais própria, íntima e intensa de relação das crianças com outras crianças, delas com elas mesmas, delas com o mundo, o que só pode acontecer em situações de brincadeira livre, sem o controle, longe da ótica produtiva do mundo adulto. As crianças precisam sentir o pulsar da vida por meio de experimentações sensoriais, de idas e vindas, repetições e inovações num tempo que precisa ser duradouro, no tempo da experiência, no tempo de cada criança. Elas precisam ir às minúcias das coisas, elas precisam ter oportunidade para vivenciar tempos mais lentos ao caminharem no mangue, na praia, ao pular em poças de lama, se atolar e sentir o tempo das idas e das vindas.

As crianças precisam se "roçar" nas coisas, experimentar por inteiro e isso só é possível quando os adultos não lhes antecipam proposições conclusivas e generalistas. Isso depende da certeza de que só a imaǵinação transcende, permite criar e também resgatar emanações mais profundas das consciências por meio de tateamentos e pulsões que permitam ao inconsciente se expressar. A imaginação convida, incita o simbólico, os mitos, as lendas, a música, as danças e as artes em geral.

Kant, ainda segundo Piorski(2013, s/p), entendeu que só a imaginação permitiria uma contrição do pensamento capaz de alcançar o suprassensível. A noção de finitude e de infinitude também só pode ser alcançada pela imaginação, não pelo pensamento lógico, para além da temporalidade da consciência humana.

Vimos nascer, portanto, nos séculos XIX e XX uma "hiperatrofia" da sensibilidade da experiência, da intuição e dos sentidos. Encarado o desafio, é possível entender a importância de discussões como essas, de cunho mais "humanizador" e, também, de reflexão sobre o próprio conceito de experiência.

0 termo "experiência", muito utilizado em processos educativos, acaba esvaziado e artificial quando reduzido a propostas/desafios disciplinadores, didatizados, que não envolvem as crianças por inteiro, nem lhes garantem o tempo duradouro e necessário às suas experiências criadoras. Nesse viés, ampliar o conceito de experiência inclui a possibilidade de as crianças mesmas narrarem os fatos, os sonhos, os medos na primeira pessoa, protagonizarem com a força da suas próprias imagens e representações. Experiências são definidas por Larrosa(2002) como ações por inteiro, duradouras e profundas que deixam 
marcas nas crianças, que lhes afetam e, para que isso se lhes aconteça, em geral, é necessário garantir o tempo de brincar livre como um direito para que possam viver "alguns riscos e uma travessia".

\section{Conclusão}

Como já dito, esse trabalho teórico-prático que vem se desenvolvendo desde 2017, na Universidade do Estado do Rio de Janeiro (UERJ), na Graduação de Pedagogia, está nesse momento exatamente na metade do caminho. Pelo menos até 2019 deveremos continuar estudando, conhecendo e aprendendo no passo, estruturando o caminho enquanto caminhamos.

0 maior desafio para nós tem sido esse enfrentamento necessário com a Filosofia, a Psicologia, a Cultura e a Sociologia da Infância. Tentamos não desconsiderar certos suportes teóricos mais próximos, como os estudos de Vygotsky, Benjamin e de Winnicott, por exemplo, já consagrados pela Educação. Essa aproximação com a Filosofia tem se tornado uma experiência que vale mesmo como uma travessia, um atravessamento de mares desconhecidos e com muitos riscos, parafraseando Larrosa.

Vygotsky, Benjamin e Winnicott foram citados apenas pelo reconhecimento legítimo e facilitado de que suas ideias, embora nascidas em países, tempos e culturas diferentes, já tenham sido mais apropriadas pela Educação. Estes autores também ajudaram muito no reconhecimento da fantasia e da imaginação como fatores de subjetivação dos sujeitos. A formação frágil, ou inexistente, em Filosofia, caracteriza o meu percurso na Educação e, com diferentes intensidades e texturas, o percurso dos alunos desse grupo e disciplina e, certamente, o da maioria dos cursos de Pedagogia.

Nesse percurso, o desafio maior consistiu em buscar não nos agarrarmos "nas cascas", na superfície dos símbolos e das imagens diante da certeza de que não estamos buscando alcançar respostas objetivas, nem quantificáveis. Para isso, fomos buscar autores e estudiosos da Filosofia, da Literatura e da Arte que não eram ainda conhecidos pelo grupo e que são pouco estudados ainda pela Educação. Compramos alguns livros, iniciamos as leituras e discussões e a primeira consequência tangível dessa experiência está aqui apresentada, cientes de que muito ainda está por ser enfrentado, em especial na relação com a Filosofia e com a Arte, para entendermos e respeitarmos as crianças por inteiro. 
Temos, ainda, já minimamente organizado, um levantamento qualitativo feito com quase duzentas crianças sobre o que, para cada uma delas, não poderia faltar nesses "espaços públicos de brincar", que podem ser praças ou não. Confirmamos a hipóteses de que as crianças de famílias com menor poder aquisitivo, que vivem em áreas de Índice de Desenvolvimento Humano (IDH) mais baixos da cidade do Rio de Janeiro, por exemplono bairro de Vargem Pequena, próximo à Lagoa do Camorim, na zona oeste da cidade, e, também, na zona norte da cidade, na área coberta pela $5^{\text {a }}$ Coordenadoria Regional de Educação (Vila da Penha, Tomas Coelho, Rocha Miranda, Madureira e cercanias) estabelecem dinâmicas diferentes em relação aos usos dos espaços de brincar, na cidade, quando comparadas às que vivem na zona sul. Até a nomenclatura "pracinha" é menos usada por eles se comparadas às crianças que vivem em outros bairros da cidade, com IDH mais altos, que têm praças melhor organizadas, às vezes com "brinquedos de toras", comum a muitas delas. As crianças da zona norte e oeste se apropriam de espaços vazios como terrenos baldios, casas abandonadas, matas e identificam ali mais um ponto de encontro com os amigos, para brincar. 0 nome do espaço usado pelas crianças, em geral, tem referência com a sua localização, como, por exemplo, o campo do shopping (fica atrás e na direção do shopping), a florestinha e a garagem, este último referindo-se a um espaço que há 30 anos teria sido uma garagem de ônibus.

Em outro momento, no futuro, quando dermos por concluída essa elaboração exposta aqui, sempre como uma carta de intenções, jogando luz sobre os caminhos escolhidos, que podem sempre ser modificados, poderemos intensificar os estudos por alguma outra vertente que não sabemos identificar ainda.

Um último ponto se refere ao que o senso comum chama de "socialização", termo amplamente usado por pais, pelas famílias e também por professores: as crianças precisam sair de casa para brincar "na rua" para se socializarem, as crianças devem ir à escola para se socializarem ou as crianças precisam se socializar para não viverem como "bichinhos" como sendo expressões comuns, recorrentes, expostas pelos adultos nos espaços públicos de brincar. Isso veio a exigir uma análise crítica do conceito de socialização devido a sua importância ser real, mas muito maior e mais complexa do que o simples aprendizado das regras sociais. Assim, o grupo vem trabalhando com uma compreensão de socialização como um processo complexo, que não pode mais ser entendido como um modelo vertical único de imposição de valores e de condutas dos adultos em relação às crianças. Nesse 
viés, socialização, nesse trabalho, é entendida como um modelo complexo que toma as crianças como sujeitos e atores sociais capazes de criar e de mudar culturas.

Pensando em um desdobramento necessário, cremos que esse estudo ainda deverá chegar às instituições de educação infantil para discutir e propor, junto com as crianças, e em respeito a elas, a existência de tipo(s) de ambiência(s) consideradas como fundamentais, em cada caso, para as práticas educativas da infância. Nas instituições escolares, tanto quanto nos espaços da cidade, as características e demandas de cada comunidade deveriam ser consideradas e as crianças sempre ouvidas e respeitadas no seu direito de participação na vida social. Em que lugares e como devem ser organizados esses espaços de brincar na cidade, para cada um dos grupos de crianças, em cada canto da cidade do Rio de Janeiro?

Não esperamos estabelecer verdades fechadas nem grandes generalizações, mas entendemos que com esse estudo poderemos contribuir para subsidiar as práticas educativas voltadas para a infância, respeitando sempre as especificidades e as culturas locais.

$\mathrm{Na}$ verdade, nunca as crianças estiveram tão presentes nos discursos acadêmicos e nas pautas sociais. Nunca foram tão valorizadas nas diferentes configurações familiares de que são parte. Apesar disso, não podemos esquecer que muitas delas ainda vivem pelas ruas, em situação de miséria e de abandono, sem família substituta e sem abrigo, invisíveis aos olhos dos adultos, à vida cotidiana das cidades e, também, aos olhos do poder público.

\title{
REFERÊNCIAS BIBLIOGRÁFICAS
}

\author{
ALANA, Instituto;TERRITORIO DO BRINCAR - Entrevista \\ GandhyPiorski,Palestra Completa, parte 1- 4, 2013. \\ Disponível https://youtu.be/5Fb1iF1_9Z0
}

BACHELARD, G. A terra e os devaneios do repouso. Ensaio sobre as imagens da intimidade. SP: Ed Martins Fontes, $2^{a}$ edição, 2003. 
BAUDELAIRE,C. Obras estéticas: filosofia da imaginação criadora. RJ: Ed. Vozes, 1993.

BRASIL. Ministério da Educação. Base Nacional Curricular Comum de Educação Infantil. Disponívelem:http:// basenacionalcomum.mec.gov.br/wp-content/ uploads/2018/02/bncc-20dez-site.pdf. Acesso em 20/08/2018

Ministério da Educação. Diretrizes Curriculares Nacionais da Educação Infantil.Brasília, DF: MEC/SEF/COEDI, 2010.Disponível em:http://portal.mec.gov.br/docman/julho2013-pdf/13677-diretrizes-educacao-basica-2013-pdf/file Acesso em 20/08/2018

BROUGERE, G. Brinquedo e cultura. SP: Editora Cortez, 2004.

CAROLYN, E.;GANDINI, L.; FORMAN, G. As cem linguagens da criança. Porto Alegre: Penso Editora, 2016.

COLOM, A..;BALLESTER, BENJAMIN, L.W. Filosofía y pedagogía. SP: Editora Cortez, 2016.

DELORME, M. I. C.; BORBA, A. M. Infância fora da asa. RJ: Editora Multifoco, 2017.

GHANDY, P. Brinquedos do chão: a natureza, o imaginário e o brincar. SP: Instituto

Alana/Editora Peirópolis, 2016.

LARROSA, B. J." Notas sobre a experiência e o saber de experiência". Revista Brasileira de Educação. Rio de Janeiro, n. 19, jan./fev./mar./abr., p. 20-28, 2002.

LOUV, R. A última criança na natureza. SP: Editora Aquariana, 2016.

RIBEIRO, R. Entrevista Francesco Tonucci: a criança como paradigma de uma cidade para todos. Disponível em: http:// 
cidadeseducadoras.org.br/reportagens/francesco-tonuccia-crianca-como-paradigma-de-uma-cidade-para-todos/ Acesso em 20/08/2018

TONUCCI, F. Com olhos de criança.Porto Alegre: Artmed, 1997.

Entrevista disponível na Internet desde 2016 em:http://cidadeseducadoras.org.br/reportagens/ francesco-tonucci-a-crianca-como-paradigma-de-umacidade-para-todos/Acesso em 20/08/2018

WINNICOT, D.W. - Da Pediatria à Psicanalise. RJ: Ed Imago, 2000

O Brincar \& a Realidade. RJ: Ed. Imago, 1975

JUNG, C.G. Obra Completa: Os Arquétipos e o Inconsciente Coletivo: Volume 9, RJ: Editora Vozes, 2014.

O Homem e seus Símbolos, Ed. Nova Fronteira, RJ: 2015

VYGOSTSKY, L S. Imaginação e criatividade na infância. SP: Editora Martins Fontes, 2018.

Recebido: 20/09/2018

Revisto: 05/11/2018

Aceito: $26 / 10 / 2018$

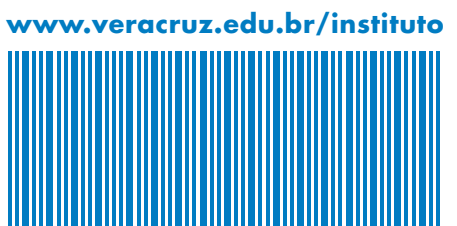

